CLINICAL STUDY

\title{
Beneficial effects of sorafenib on tumor progression, but not on radioiodine uptake, in patients with differentiated thyroid carcinoma
}

\author{
Hendrieke Hoftijzer $^{1}$, Karen A Heemstra ${ }^{1}$, Hans Morreau ${ }^{2}$, Marcel P Stokkel ${ }^{3}$, Eleonora P Corssmit ${ }^{1}$, \\ Hans Gelderblom $^{4}$, Karin Weijers ${ }^{2}$, Alberto M Pereira ${ }^{1}$, Maya Huijberts ${ }^{5}$, Ellen Kapiteijn ${ }^{4}$, Johannes A Romijn ${ }^{1}$ \\ and Johannes W Smit ${ }^{1}$ \\ Departments of ${ }^{1}$ Endocrinology and Metabolism, C4-R, ${ }^{2}$ Pathology, ${ }^{3}$ Nuclear Medicine and ${ }^{4}$ Oncology, Leiden University Medical Center, PO Box 9600 , \\ 2300 RC Leiden, The Netherlands and ${ }^{5}$ Department of Endocrinology, Maastricht University Medical Center, Maastricht, The Netherlands \\ (Correspondence should be addressed to J W A Smit; Email: jwasmit@lumc.nl)
}

(H Hoftijzer and K A Heemstra contributed equally to this work)

\begin{abstract}
Objective: Treatment options for patients with radioactive iodine (RaI) refractory metastases of differentiated thyroid carcinoma (DTC) are limited. We studied the effects of the multitarget tyrosine kinase inhibitor sorafenib on the reinduction of RaI uptake and tumor progression.

Design: Open, single center, single arm 26-week prospective phase II study with open-ended extension. Methods: We treated 31 patients with progressive metastatic or locally advanced RaI refractory DTC with sorafenib $400 \mathrm{mg}$ b.i.d. The primary endpoint was reinduction of RaI uptake at 26 weeks. Additional endpoints were the radiological response and the influence of bone metastases.

Results: At 26 weeks of sorafenib therapy, no reinduction of RaI uptake at metastatic sites was observed, but 19 patients (59\%) had a clinical beneficial response, eight of whom had a partial response $(25 \%)$ and 11 had stable disease (34\%). Seven patients had progressive disease $(22 \%)$. Sorafenib was significantly less effective in patients with bone metastases. The estimated median progression free survival was 58 weeks (95\% confidence interval, CI, 47-68). In general, thyroglobulin $(\mathrm{Tg})$ response (both unstimulated and TSH stimulated) reflected radiological responses. The median time of the nadir of $\mathrm{Tg}$ levels was 3 months. Responses were not influenced by histological subtype, mutational status or other variables. No unusual side effects were observed.

Conclusions: Sorafenib has a beneficial effect on tumor progression in patients with metastatic DTC, but was less effective in patients with bone metastases. Diagnostic whole body scintigraphy did not reveal an effect of sorafenib on the reinduction of RaI uptake.
\end{abstract}

European Journal of Endocrinology 161 923-931

\section{Introduction}

The prognosis of differentiated thyroid carcinoma (DTC) in general is favorable due to the efficacy of the combined treatment of surgery and radioactive iodine (RaI) and the biological behavior of the tumor $(1,2)$. However, $\sim 50 \%$ of patients with distant metastases of DTC die within 10 years of diagnosis (3). Although the role of RaI in recurrent or metastatic thyroid cancer is beyond dispute (4-6), the efficacy of this therapy is hampered by the decreased expression of the sodium iodide symporter (NIS) in DTC during the process of dedifferentiation (7-9). Predictive factors for responsiveness to RaI treatment include a younger age, small metastases, well-differentiated thyroid tumor histology and the absence of uptake of 18-fluoro deoxyglucose (FDG) at FDG-positron emission tomography (PET) scanning. Especially in patients with bone metastases, the efficacy of RaI is limited to $7-20 \%$ of the patients $(4,6,10,11)$. At present, there are no effective therapies available for RaI non-avid DTC. Conventional chemotherapy is hardly effective in DTC, and no longer recommended in international guidelines $(12,13)$.

In DTC, many genetic alterations have been identified, involving tyrosine kinase signaling pathways (14-16). In nearly all cases of papillary thyroid carcinoma (PTC), genetic defects involving the RET, RAS, and RAF protein kinase signaling cascade are identified. The $\mathrm{BRAF}^{\mathrm{V} 600 \mathrm{E}}$ mutation has been found in 29-69\% of PTC and has been associated with aggressive features including extrathyroidal extension and advanced stage (17). Translocations of RET observed in PTC result in a chimeric protein consisting of an activated RET tyrosine kinase domain (15, 18-32). Follicular thyroid carcinomas (FTC) frequently harbor mutations in one of the three RAS genes. 
The RET-RAS-RAF pathway is interconnected with the epithelial growth factor receptor (EFGR) activated cascade that among others leads to vascular endothelial growth factor (VEGF) and VEGF receptor (VEGFR) synthesis. Therefore, compounds targeting the activated RET-RAS-RAF pathway and beyond may be effective in non-RaI avid DTC. The anti-EGFR compound gefitinib was not successful in 27 patients with DTC, medullary or anaplastic thyroid carcinoma (33). In a phase II study in 60 thyroid carcinoma patients with various histologies, the VEGFR inhibitor axitinib showed a partial response of $30 \%$ (median progression free survival (PFS) 18 months) (34). Recently, 3 phase II studies have been published, using multi-kinase inhibitors (35-37). Motesanib diphosphate induced a partial response in 14\% of 93 DTC patients (median PFS 40 weeks) (36). Two studies have been published using sorafenib. Sorafenib (BAY 43-9006) is an inhibitor of RET, CRAF, wild-type and mutant (V600E) BRAF, VEGFR1, -2, -3, Flt3, and c-KIT.

In the first study, including DTC, anaplastic and medullary thyroid carcinoma patients, sorafenib induced a partial response in 23\% (median PFS 79 weeks). In the second study, including patients with DTC and anaplastic thyroid carcinoma, a partial response was observed in 11\% (median PFS 4.5-16 weeks) (37). As bone metastases of DTC are poorly responsive to RaI, the response of bone metastases to the above-mentioned therapies is of interest. However, there were no separate analyses for patients with bone metastases in the above-mentioned studies.

In DTC, a relationship has been identified between genetic alterations in the RET, RAS, RAF cascade and loss of NIS expression $(17,38)$. Interestingly, in an in vitro study, sunitinib was able to reinduce NIS expression in RET/PTC transformed thyroid cells (39). In addition, sunitinib also increased RaI uptake in FRTL- 5 cells. We therefore hypothesized that treatment with a multiple kinase inhibitor not only reduces tumor progression, but may also restore RaI uptake in non-RaI avid DTC. Therefore, we performed a single arm phase II trial to determine the efficacy of sorafenib in patients with iodinerefractory metastatic DTC, focusing on the reinduction of $\mathrm{RaI}$ uptake and the efficacy in bone metastases.

\section{Patients and methods}

\section{Patients}

Eligibility criteria for the present study were the presence of progressive metastases or unresectable local recurrence of DTC for which RaI therapy was no longer effective, as indicated by prior negative post-therapeutic whole body scintigraphy (WBS). Progressive disease was defined according to response evaluation criteria in solid tumors (RECIST) criteria in the year before initiation of treatment. Patients who were selected, had to have undergone total thyroidectomy and RaI ablative therapy. Exclusion criteria were pregnancy, contraindications for the application of recombinant human thyrotropin (rhTSH) and contraindications for the use of sorafenib. In addition, no patients with poorly responsive DTCs were included as it was hypothesized that the likelihood of reinduction of RaI uptake in this category of tumors would be very small. Other eligibility criteria included Eastern Cooperative Oncology Group performance status $0-2$ and life expectancy more than 3 months. Patients were ineligible if they had previous exposure to biological therapies. All patients provided written informed consent before enrollment onto the trial. The study protocol was approved by the Institutional Review Board of the Leiden University Medical Center. This study has been registered at ClinicalTrials.gov (\# NCT00887107).

\section{Study design}

The study was a 26-week open-label, single-arm, phase II study of oral sorafenib in patients with metastatic DTC. The primary objective was to study the effect of sorafenib treatment on reinduction of radioiodine uptake. Secondary objectives were radiological tumor response according to RECIST and the relation between the presence of bone metastases and therapy success. Sorafenib was initially administered at a dose of $400 \mathrm{mg}$ orally twice a day. Eligibility assessments, including a review of medical history and prior treatments, physical examination and laboratory assessments were completed within 2 weeks before initiation of the sorafenib therapy. Baseline radiological evaluation by computed tomography (CT) of target lesions was performed 4 weeks prior to initiation of therapy. From all patients, tumor samples from the primary tumors were obtained for review by the institutional pathologist $(\mathrm{H} \mathrm{M})$. After inclusion, the patients underwent a diagnostic scintigraphy 3 days after i.v. administration of $185 \mathrm{MBq}$ I-131 (Mallinckrodt BV, Petten, The Netherlands). Single photon emission computed tomography (SPECT) of the head and neck and chest was performed. Two experienced observers visually analyzed all images. An I-131 standard was used to quantify the uptake in the area of interest at WBS. Patients were prescribed a low iodide diet from 7 days prior to the administration of I-131 (40). The patients received i.m. injections with $0.9 \mathrm{mg}$ rhTSH (Thyrogen, Genzyme, Naarden, The Netherlands) on two consecutive days before the RaI administration. The day after the first WBS, patients started treatment with sorafenib $400 \mathrm{mg}$ bid. Twenty-six weeks after initiation of sorafenib therapy, CT scanning and RaI imaging studies were repeated. All target lesions were imaged using CT. According to RECIST criteria, bone lesions were not evaluated as target lesions. It was carefully planned that CT scans using i.v. contrast were performed after diagnostic RaI scintigraphies. Procedures to exclude 
the occurrence of new bone metastases included bone and FDG-PET scintigraphy. Patients visited the hospital every 4 weeks for physical examination and assessment of laboratory safety parameters. Patients were assessed for new symptoms, compliance with study medications, and concomitant medications. Dose adjustments were made as needed for toxicity. The target serum TSH levels were below $0.1 \mathrm{mU} / \mathrm{l}$. After completion of 26-week treatment, patients were allowed to continue sorafenib treatment, when a favorable response (complete or partial remission, or stable disease) had been achieved, until progression according to RECIST criteria. Adverse events were graded with the use of Common Terminology Criteria for Adverse Events (version 3).

To study the relation between efficacy and tumor mutational state, tumor DNA from patients was isolated from the paraffin-embedded material by taking tissue punches (diameter, $0.6 \mathrm{~mm}$ ) with a tissue microarrayer (Beecher Instruments, Silver Springs, MD, USA) from tumor and normal areas selected on the basis of a hematoxylin eosin (HE)-stained slide. Mutational analysis was performed using PCR amplification followed by sequencing on an ABI 3730 automated sequencer (Applied Biosystems, Foster City, CA, USA) ABI 3700. Codons investigated were: B-type Raf kinase (BRAF, V600E and exon 11), HRAS (codon 12/13 and 61), KRAS (codon 12/13 and 61), NRAS (codon 61), and phosphatidylinositol-3-kinase, catalytic, alpha polypeptide (PIK3CA, exons 9 and 20). Primer sequences are available on request.

\section{Laboratory parameters}

The following laboratory parameters were assessed: serum TSH, free-thyroxine $\left(\mathrm{T}_{4}\right)$, thyroglobulin $(\mathrm{Tg})$, and $\mathrm{Tg}$ antibody levels were measured at all visits. TSH and Tg were also measured 1 and 3 days after the last rhTSH injection. Safety parameters were assessed at every visit and included a hematological profile as well as serum levels of sodium, potassium and creatinine in lipids, renal and liver function. Serum TSH was determined with a Modular Analytics E-170 system ((Roche Diagnostic Systems), intra-assay variability: 0.9-10.7\%, interassay variability: 0.9-12.1\%). Serum $\mathrm{Tg}$ was determined with IRMA ((Tg kit, Brahms, Berlin, Germany) on a Wallac (Wallac, Turku, Finland), intra-assay variability: $0.1-13.9 \%$, interassay variability: $12.3-17.4 \%)$. Serum Tg antibodies were determined with IRMA (Sorin Biomedica, Amsterdam, The Netherlands) on a Wallac (Wallac, Turku, Finland, intra-assay variability: 3.6-4.1\%, interassay variability: $11.6 \%$ ).

\section{Statistical methods}

Using a Simon two-stage design, the study required 24 subjects to decide whether the proportion responding, $P$, is $\leq 10 \%$ or $\geq 40 \%$. If the number of responses was six or more, the hypothesis that $P \leq 10 \%$ is rejected with a target error rate of $5 \%$ and an actual error rate of $2.8 \%$. If the number of responses was five or less, the hypothesis that $P \geq 40 \%$ is rejected with a target error rate of $5 \%$ and an actual error rate of $4 \%$. All enrolled patients were included in an intention-to-treat analysis. Data are reported as mean \pm s.D., median (range) or proportions. Estimates of PFS (time from starting study drug to progression) with associated 95\% CIs were obtained using the Kaplan-Meier method. Analyses of variables influencing response to sorafenib were analyzed with binomial logistic regression (26-week data). The calculations were performed using SPSS 16.0 for Windows (SPSS, Chicago, IL, USA).

\section{Results}

Between 13 October 2007 and 7 October 2008, a total of 31 patients started sorafenib treatment (Fig. 1). One patient chose not to start sorafenib therapy after giving signed informed consent. Therefore, 32 patients were included in the intention-to-treat analysis. A total of 22 patients completed 26 weeks of treatment. The remaining patients discontinued treatment earlier because of disease progression (four patients, see efficacy section for details), drug-related adverse events

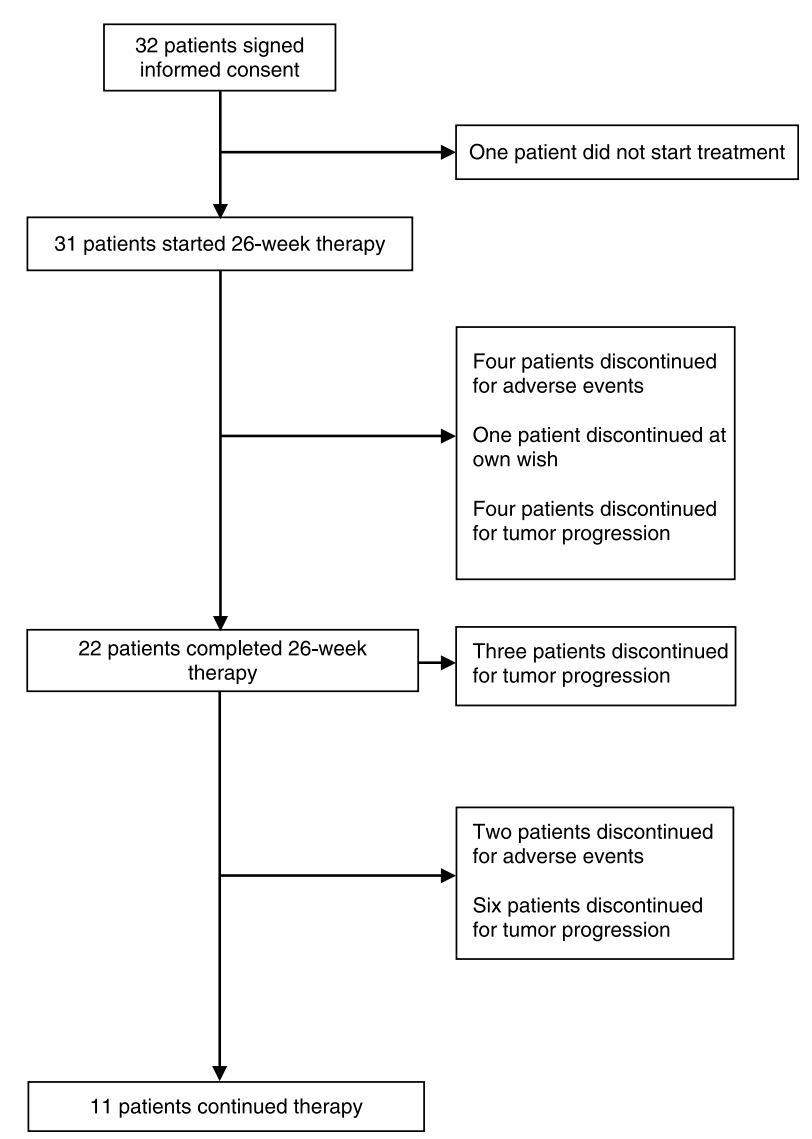

Figure 1 Study flowchart. 
(two patients, see adverse events section for details), non-drug related adverse events (two patients) or the patient's request (one patient). Eight of the 22 patients who completed the 26-week trial and continued sorafenib treatment, discontinued treatment later on, two because of adverse events and six because of disease progression. The median duration of sorafenib treatment for all patients was 32 weeks (range 3 days to 79 weeks). Median duration of follow-up was 63 weeks (range 28-80 weeks).

Baseline characteristics are given in Table 1. All patients had undergone prior RaI treatments with a median activity of 15.2 (range 3.7-30.0) GBq. The number of RaI treatments ranged from 1 to 4 . None of the patients had RAI uptake before inclusion as indicated by post-therapeutic WBSs and at baseline. Fifteen patients had undergone external beam irradiation. In all patients, external beam irradiation was aimed at one or more bone metastases. As no bone metastases were target lesions this treatment did not interfere with the assessment of efficacy.

Interestingly, the most common histologic carcinoma subtype was Hürthle cell carcinoma. In follicular thyroid with Hürthle cell metaplasia, the majority of cells were Hürthle cells. At study entry, almost all patients had lung metastases $(n=30)$, whereas 14 patients had bone metastases. Most patients had metastases at multiple sites. In 10/13 patients PTC's $\mathrm{BRAF}^{\mathrm{V} 600 \mathrm{E}}$ mutations were identified, one of which (the tall cell variant) also showed a PIK3CA mutation.

Table 1 Baseline characteristics.

\begin{tabular}{|c|c|}
\hline & $\begin{array}{l}\text { All patients } \\
(n=32)\end{array}$ \\
\hline \multicolumn{2}{|l|}{ Gender (no.; \%) } \\
\hline Female & $13(39)$ \\
\hline Male & $19(61)$ \\
\hline Time from diagnosis (year; median, range) & $3(0-18)$ \\
\hline Age (year; median, range) & $65(53-82)$ \\
\hline \multicolumn{2}{|l|}{ Histology (no.; \%) } \\
\hline Papillary & $13(41)$ \\
\hline Tall cell & $1(3)$ \\
\hline Hürthle cell metaplasia & $2(6)$ \\
\hline Follicular variant papillary & $3(9)$ \\
\hline Follicular & $15(47)$ \\
\hline Hürthle cell metaplasia & 11 (34) \\
\hline Mixed papillary follicular & $1(3)$ \\
\hline \multicolumn{2}{|l|}{ Initial TNM stage (no.; \%) (5 unknown) } \\
\hline $\mathrm{T}_{1-3} \mathrm{NO} / 1 \mathrm{MO}$ & $12(44)$ \\
\hline $\mathrm{T}_{4} \mathrm{NO} / 1 \mathrm{MO}$ & $6(23)$ \\
\hline M1 & $9(33)$ \\
\hline \multicolumn{2}{|l|}{ Tumor extent at study entry (no.; \%) } \\
\hline Thyroid bed only & $1(3)$ \\
\hline Lungs only & $8(25)$ \\
\hline Lungs and bones only & $7(22)$ \\
\hline Locally advanced ${ }^{\mathrm{a}}$ and distant metastases & $9(33)$ \\
\hline Other & $7(22)$ \\
\hline Radioiodine dose (GBq, median, range) & $15.2(3.7-30.0)$ \\
\hline External beam radiation (no.; \%) & $15(47)$ \\
\hline
\end{tabular}

${ }^{\mathrm{a}}$ Including both thyroid bed $(n=5)$ and neck lymph nodes $(n=4)$.
Few additional mutations were identified: one KRAS in FVPTC; two NRAS mutations were found (one in a PTC without a BRAF mutation and one in a FTC); and one additional PIK3CA mutation was found in a FTC with Hürthle cell metaplasia.

\section{Efficacy}

Data on responses are given in Table 2 and Fig. 2. Disease progression led to treatment discontinuation of patients at 6 weeks (one patient with new bone metastases), 18 weeks (one patient with a new abdominal metastasis, one patient with new pulmonary metastases), 25 weeks (one patient with cerebral metastases), 26 weeks (end of 26-week trial: two patients with new bone metastases, one patient with a new pulmonary metastasis), 32 weeks (two patients with new bone metastases, one patient with progression of a hip lesion, one patient with new liver metastases and one patient with new lung lesions) and 40 weeks (one patient with a new neck lesion).

At 26 weeks, 19 patients (59\%) had achieved a clinical beneficial response, eight of whom had a partial response $(25 \%)$ and 11 had stable disease (34\%; Table 2). There were no complete responses. At 26 weeks, the cumulative number of patients with progressive disease was seven. Interestingly, four patients with progressive disease based on new lesions had no progression or a considerable decrease in the sum of the longest diameter of target lesions. Radiological response at 26 weeks was not influenced by gender $(P=0.593)$, age $(P=0.172)$, initial tumour lymphnodes metastases (TNM) stage $(P=0.488)$, histology $(P=0.614)$, or the presence of the BRAF ${ }^{\mathrm{V} 600 \mathrm{E}}$ mutation $(P=0.760)$. The prevalence of other mutations was too low to allow statistical analysis. However, when bone metastases were present, the response to sorafenib was significantly worse than in the absence of bone metastases $(P=0.004$, Table 2). Although this study was not formally designed for the establishment of PFS, estimation of median PFS was 58 weeks (95\% CI, 47-68). Likewise, PFS was influenced by the presence of bone metastases. PFS was 69 weeks (CI: 58-80) in patients without bone metastases and 47 weeks (CI: 32-62) in patients with bone metastases $(P=0.046)$.

In general, $\mathrm{Tg}$ response reflected radiological response and there were no differences between the responses of unstimulated versus TSH stimulated Tg measurements (Table 2, Fig. 2). The median time of the nadir of Tg levels was 3 months. The median change in $\mathrm{Tg}$ at 26 weeks versus baseline was $-16 \mu \mathrm{g} / \mathrm{l}$ (range -2746 to 17836 ). Remarkably, one patient with progression in a non-target lesion had a decrease in unstimulated Tg, but an increase in TSH stimulated Tg. In one 54-year-old woman with pulmonary metastases of a Hürthle cell FTC, a remarkable rise in serum Tg from 1664 to $99900 \mu \mathrm{g} / \mathrm{l}$ was observed 8 weeks after 
Table 2 Tumor response.

\begin{tabular}{|c|c|c|c|c|c|c|c|c|}
\hline \multirow{3}{*}{$\begin{array}{l}\text { Reinduction of } \\
\text { radioiodine uptake } \\
\text { at } 26 \text { weeks }\end{array}$} & \multirow{3}{*}{$\begin{array}{l}\text { All patients } \\
(n=32)\end{array}$} & \multicolumn{2}{|c|}{ Bone metastases } & \multicolumn{5}{|c|}{ Histology ${ }^{a}$} \\
\hline & & \multirow{2}{*}{ Absent } & \multirow{2}{*}{ Present } & \multicolumn{2}{|c|}{$\begin{array}{l}\text { Papillary thyroid } \\
\text { carcinoma (PTC) }\end{array}$} & \multirow{2}{*}{$\begin{array}{c}\text { Follicular } \\
\text { variant } \\
\text { PTC }\end{array}$} & \multicolumn{2}{|c|}{$\begin{array}{l}\text { Follicular thyroid } \\
\text { carcinoma (FTC) }\end{array}$} \\
\hline & & & & Total & $\begin{array}{l}\text { Hürthle cell } \\
\text { metaplasia }\end{array}$ & & Total & $\begin{array}{l}\text { Hürthle cell } \\
\text { metaplasia }\end{array}$ \\
\hline \multicolumn{9}{|c|}{ Radiological response ( $n$; \% of total patients) } \\
\hline Complete response & $0(0)^{b^{\prime}}$ & $0(0)$ & $0(0)$ & $0(0)^{c}$ & 0 & $0(0)$ & $0(0)$ & 0 \\
\hline Partial response & $8(25)$ & $5(16)$ & $3(9)$ & $2(22)$ & 0 & $2(67)$ & $4(49)$ & 4 \\
\hline Stable disease & $11(34)$ & $7(22)$ & $4(13)$ & $6(67)$ & 1 & $0(0)$ & $5(36)$ & 3 \\
\hline Clinical benefit & $19(59)$ & $12(38)$ & $7(22)$ & $8(89)$ & 1 & $2(67)$ & $9(64)$ & 7 \\
\hline Progressive disease & $7(22)$ & $0(0)$ & $7(22)^{*}$ & $1(11)$ & 0 & 1 (33) & $5(36)$ & 3 \\
\hline \multicolumn{9}{|c|}{ Serum thyroglobulin levels $(\mu \mathrm{g} / \mathrm{l})$} \\
\hline Baseline (median; range) & $77(4.4-8570)$ & & & & & & & \\
\hline 26 -weeks $(n=22)$ & $46(0.9-19500)$ & & & & & & & \\
\hline $\begin{array}{l}\text { Delta } \mathrm{Tg} \text { (versus } \\
\text { baseline, median, range) }\end{array}$ & $-16(-2746-17836)$ & & & & & & & \\
\hline Nadir & $29(0.5-7634)$ & & & & & & & \\
\hline $\begin{array}{l}\text { Time to nadir (months, } \\
\text { median, range) }\end{array}$ & $3(0-5)$ & & & & & & & \\
\hline $\begin{array}{l}\text { Progression free survival } \\
\text { (weeks, median, } \mathrm{Cl} \text { ) }\end{array}$ & $58(47-68)$ & & & & & & & \\
\hline
\end{tabular}

${ }^{\star} P=0.005$ versus no bone metastases.

${ }^{a}$ One patient with mixed PTC and FTC left the study because of an adverse event and could not be evaluated.

${ }^{\mathrm{b}}$ Percentage of total $(n=32)$ patients.

cPercentage of evaluable patients per histology class.

initiation of therapy. A chest CT scan revealed an impressive decrease in the number, size, and density of all pulmonary metastases.

Reinduction of radioiodine uptake could be evaluated in 21 patients who had completed 26-week treatment with sorafenib. In one patient, WBS could not be performed for technical reasons. In three patients with extensive metastases, both at baseline and at 26 weeks, RaI WBS revealed uptake at the thyroid bed, but not at the sites of metastases. In 20 patients, there was no RaI uptake at metastatic sites after 26 weeks of sorafenib therapy. In one patient with an occipital skeletal metastasis that did not accumulate RaI at baseline, very slight RaI uptake was observed at 26 weeks. However, a post-therapeutic WBS performed after subsequent $7600 \mathrm{MBq}$ RaI therapy did not reveal any uptake, and consequently it was concluded that no clinically relevant reinduction of RaI therapy had occurred in this patient.

\section{Adverse events}

Adverse events led to discontinuation of the study in six patients at respectively 3 weeks (angioedema), 5 weeks (myocardial infarction), 7 weeks (hematuria), 12 weeks (concomitant small cell lung carcinoma), 38 weeks (dyspnea, not related to tumor progression), and 50 weeks (congestive heart disease). Doses were reduced in $18(56 \%)$ patients to control toxicities. The median dose at 26 weeks was $400 \mathrm{mg} /$ day.
The most prevalent adverse events are mentioned in Table 3. The hand-foot syndrome occurred in the first few weeks of treatment and subsided in most patients after dose reduction and topical treatment. Most patients received nutritional support for weight loss. In three patients with considerable weight loss, a percutaneous gastric feeding catheter had to be inserted. Mineral deficiencies were treated with supplementation. Hypertension was treated with antihypertensive drugs. Hematological abnormalities were mild and did not require treatment. In order to maintain serum-free $\mathrm{T}_{4}$ levels and TSH levels at the required values, five patients required a thyroxine dose reduction, whereas in six patients, the dose needed to be increased. No relationship was observed between toxicity and performance state and age.

\section{Discussion}

We studied the efficacy of the multiple target tyrosine kinase inhibitor sorafenib in patients with iodinerefractory metastatic DTC, focusing on the reinduction of RaI uptake and the efficacy in patients with bone metastases. After 26 weeks of treatment, we found a partial response rate of $25 \%$ and a clinical beneficial response in $59 \%$ of the patients. Patients with bone metastases responded significantly worse. Reinduction of RaI uptake as studied by diagnostic WBS was not observed in any patient. 

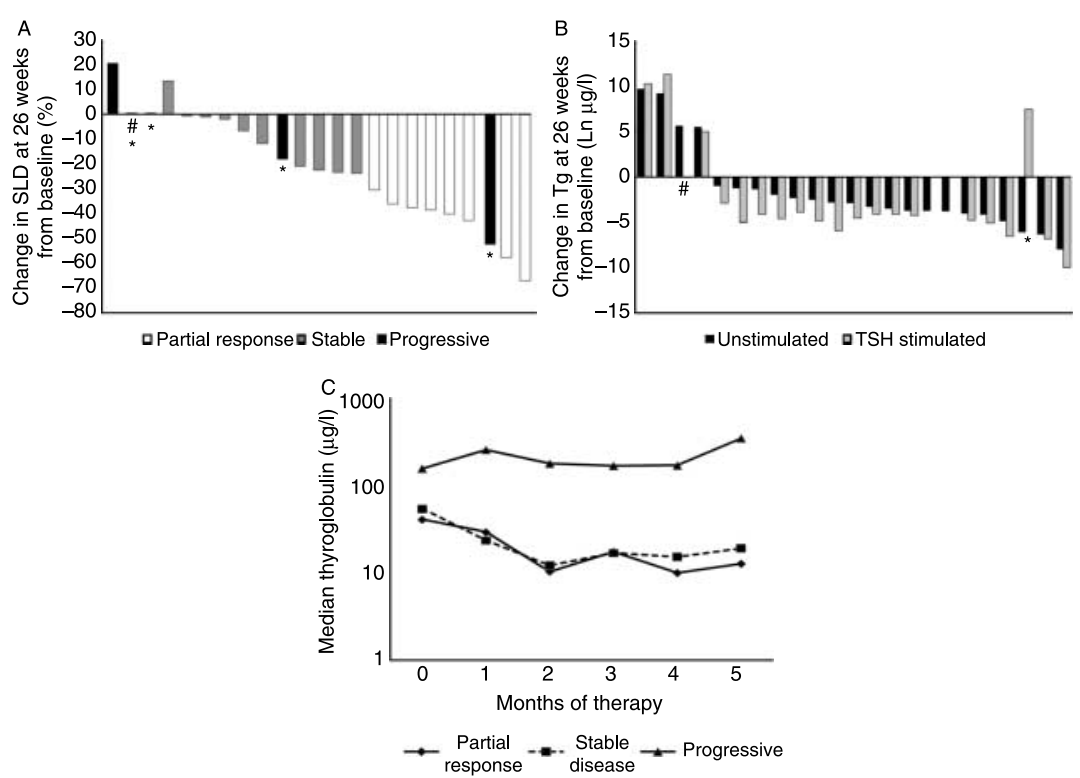

Figure 2 (A) The change from baseline in tumor dimensions (sum of longest diameters (SLD)) is shown for 22 patients who completed 26 weeks of treatment with sorafenib and one patient who discontinued treatment at 18 weeks for disease progression (new soft-tissue lesion (\#)). Not shown are data for three patients with progressive disease due to new lesions. Four patients with progressive disease based on new lesions had no progression or a considerable decrease in SLD (*). Target and non-target lesions are defined according to the response evaluation criteria in solid tumors (RECIST). (B) The natural logarithm of the change at 26 weeks from baseline in unstimulated and TSH stimulated serum thyroglobulin (Tg) levels is shown for 22 patients who completed 26 weeks of treatment with sorafenib and one patient who discontinued treatment at 25 weeks for disease progression (new cerebral metastasis (\#)). One patient with progression in a non-target lesion had a decrease in unstimulated Tg but an increase in TSH stimulated $\mathrm{Tg}\left({ }^{*}\right)$. TSH stimulated Tg measurements were performed 3 days after the last injection of $0.9 \mathrm{mg}$ rhTSH. (C) Medians of unstimulated serum thyroglobulin (Tg) levels of $25 \mathrm{evaluable}$ patients during 26 weeks of treatment with sorafenib stratified according to radiological response. Three of these patients with progressive disease discontinued treatment before 26 weeks. From one other patient, who also discontinued treatment before 26 weeks for disease progression, no $\mathrm{Tg}$ levels were obtained.

RaI therapy is the only available conventional therapy for patients with metastases of DTC. Hürthle cell carcinomas respond less favorably to RaI, which is compatible with the fact that the most prevalent histology was Hürthle cell metaplasia. The fact that 10/13 PTC harbored $\mathrm{BRAF}^{\mathrm{V} 600 \mathrm{E}}$ mutations also illustrates the unfavorable prognostic characteristic of our patient group (41). The extensive characterization in recent years of the molecular pathways involved in the pathogenesis of DTC has revealed potential targets for new therapies. The identification of tyrosine kinase activated pathways in DTC together with the advent of novel classes of tyrosine kinase inhibitors has provided new therapeutic perspectives for patients with non-RaI avid DTC. The results of our study with respect to radiological response are comparable with those observed in another study with sorafenib by Gupta et al. (35) and better than observed in the study of Kloos et al. (37). The latter study, however, included patients with anaplastic carcinoma. Comparison of the results of phase II studies with different tyrosine kinase inhibitors in DTC is hampered by differences in patient categories (including histologies, tumor stages, sites of metastases, and tumor extent), study design, and analytical methods. Nonetheless, the results obtained with sorafenib in different studies, including our own suggest that sorafenib is among the most successful and promising compounds for metastatic DTC. We found a significant difference in the response to sorafenib between patients with or without bone metastases, the latter category responding worse. Nevertheless, $23 \%$ of patients with bone metastases had a favorable response. Those patients had metastases at multiple sites, mostly pulmonary that regressed under sorafenib, whereas the bone metastases were stable.

The explanation for a less favorable response of bone metastases is not clear. It can be hypothesized that both pharmacokinetic factors (lower tissue levels in bone) and tumor-related factors are involved. As it is hardly possible to obtain tissue from bone metastases, the relationship between the genetic profile of bone metastases and responsiveness to sorafenib is not easy to study. Another explanation may be that it has been observed that the role of VEGFR signal transduction in tumor propagation in conscript vascular systems such as soft-tissue metastases may differ from less well-defined vascular beds as the bone marrow. As a consequence, VEGFR targeted therapies may have less prominent beneficial effects in bone metastases. In addition it is also conceivable that the presence of bone metastases influences the response of soft-tissue metastases to sorafenib. Although the mechanism is not 
Table 3 Adverse events.

\begin{tabular}{|c|c|c|c|c|c|}
\hline \multirow[b]{2}{*}{ Event } & \multirow{2}{*}{$\begin{array}{c}\text { All } \\
\text { Number of patients } \\
(\% \text { of total }(n=32))\end{array}$} & \multicolumn{4}{|c|}{ Grades ( $\%$ of category) } \\
\hline & & 1 & 2 & 3 & 4 \\
\hline Hand foot syndrome & $21(66)$ & 33 & 33 & 33 & 0 \\
\hline Weight loss & $18(56)$ & 35 & 50 & 15 & 0 \\
\hline Diarhoea & $16(50)$ & 31 & 69 & 0 & 0 \\
\hline Alopecia & $15(47)$ & 87 & 13 & 0 & 0 \\
\hline Rash & $15(47)$ & 60 & 40 & 0 & 0 \\
\hline Mucositis & $14(44)$ & 100 & 0 & 0 & 0 \\
\hline Hypertension & $13(41)$ & 31 & 31 & 38 & 0 \\
\hline Hypocalcemia & $13(41)$ & 100 & 0 & 0 & 0 \\
\hline Thrombopenia & $9(28)$ & 100 & 0 & 0 & 0 \\
\hline Hypophosphatemia & $9(28)$ & 100 & 0 & 0 & 0 \\
\hline Anemia & $8(25)$ & 100 & 0 & 0 & 0 \\
\hline Myocardial infarction & $1(3)$ & 0 & 0 & 0 & 100 \\
\hline Congestive heart disease & $1(3)$ & 0 & 0 & 100 & 0 \\
\hline Hematuria & $1(3)$ & 0 & 100 & 0 & 0 \\
\hline
\end{tabular}

According to Common Terminology Criteria for Adverse Events (version 3).

clear it could be hypothesized that the systemic release of proteins or cytokines, such as interleukin 6 or TGF beta from the bone microenvironment plays a role in this phenomenon.

The fact that there was a mixed response in some subjects (both regression and progression) is explained by the heterogeneous nature of metastases in thyroid carcinoma, which can be caused by tumor-related factors and the microenvironment of the metastatic site. This may lead to differences in tumor dependence on tyrosine kinase activated pathways, which may consequently lead to differences in response to sorafenib. RECIST does not take into account these phenomena, which are very important for the selection of lesions that may or may not respond to tyrosine kinase inhibitors.

Another purpose of our study was to assess the effects of sorafenib on RaI uptake. We did not find reinduction of RaI uptake in any patient. Although a clear relation has been found in vitro between genetic alterations in DTC and decreased NIS gene expression (17, 38), multiple mechanisms may be involved in decreased NIS functionality, including impaired NIS membrane trafficking $(42,43)$, epigenetic changes in NIS and/or NIS promoter genes (44). Although in vitro studies have shown that multiple target tyrosine kinase inhibitors may lead to reinduction of RaI uptake $(39,45)$, it may well be that these additional mechanisms have prevented a beneficial effect of sorafenib on RaI uptake in our study. Another explanation for the lack of an effect of sorafenib on RaI uptake may be the lower sensitivity of diagnostic WBS as compared to posttherapeutic scintigraphy. For this reason, we used SPECT acquisition in our diagnostic scintigraphies, which has a higher sensitivity than conventional WBS. Nevertheless, we cannot exclude that a limited sensitivity may indeed have contributed to our observation of a failure of sorafenib to reinduce RaI uptake. As baseline CT scans were performed 4 weeks prior to radioiodine scintigraphies, i.v. contrast could have interfered with the diagnostic scintigraphy at baseline. As no urinary iodine measurements were performed, this cannot be entirely ruled out. However, the fact that all patients had negative post-therapeutic WBSs previously ascertains the true radioiodine nonavid nature of the lesions.

Although uptake of RaI is an important determinant of tumor response, another important factor is radiosensitivity. Indeed, a subgroup of thyroid carcinomas does not respond to RaI therapy, despite RaI uptake. Genetic alterations in radiation-induced apoptotic pathways, including p-53 or cdk-21 may be involved. Therefore, in the design of redifferentiation studies in thyroid carcinoma, this aspect should always be taken into account, ideally involving genetic studies in these pathways.

Serum $\mathrm{Tg}$ levels in general paralleled radiological changes. However, tumor lysis during sorafenib or comparable compounds can lead to elevated Tg levels as was observed in one patient. This could be due to tumor lysis, but it could in theory also be caused by increased $\mathrm{Tg}$ synthesis as a result of enhanced differentiated behavior of thyroid carcinoma cells.

Although sorafenib therapy had considerable adverse effects, no unexpected or new adverse effects were observed. Most of the adverse effects were temporary and could be managed with dose reduction or therapeutic measures. Weight loss was considerable, especially in patients with low weight at baseline, requiring dietary support or even catheter feeding.

In conclusion, the results of our study confirm the potential role of sorafenib in patients with non-RaI avid metastases of DTC. In addition, we found that patients with bone metastases respond less favorably, and that 
diagnostic WBS did not reveal an effect of sorafenib on the reinduction of RaI uptake in these patients. Future phase III studies should confirm the efficacy of sorafenib for DTC.

\section{Declaration of interest}

J W Smit received a research grant from Bayer B V Mijdrecht for performing this study. The other authors have nothing to disclose.

\section{Funding}

This study was supported by a grant from Bayer B V Mijdrecht, The Netherlands (IMP 12791 19-04-2007).

\section{Acknowledgements}

We would like to express our gratitude to Mr Bienvenue Loembé, Bayer B V Mijdrecht, The Netherlands, for his technical support and Bayer B V Mijdrecht, The Netherlands, for the supply of study medication and their financial support to this study.

\section{References}

1 Schlumberger MJ. Papillary and follicular thyroid carcinoma. New England Journal of Medicine 1998338 297-306.

2 Mazzaferri EL \& Kloos RT. Clinical review 128: current approaches to primary therapy for papillary and follicular thyroid cancer. Journal of Clinical Endocrinology and Metabolism $2001 \mathbf{8 6}$ 1447-1463.

3 Hundahl SA, Fleming ID, Fremgen AM \& Menck HR. A National Cancer Data Base Report on 53,856 cases of thyroid carcinoma treated in the U.S., 1985-1995. Cancer $1998832638-2648$.

4 Pacini F, Cetani F, Miccoli P, Mancusi F, Ceccarelli C, Lippi F, Martino E \& Pinchera A. Outcome of 309 patients with metastatic differentiated thyroid carcinoma treated with radioiodine. World Journal of Surgery $1994 \mathbf{1 8}$ 600-604.

5 Schlumberger M, Challeton C, De Vathaire F \& Parmentier C. Treatment of distant metastases of differentiated thyroid carcinoma. Journal of Endocrinological Investigation $1995 \mathbf{1 8}$ $170-172$.

6 Schlumberger M, Challeton C, De Vathaire F, Travagli JP, Gardet P, Lumbroso JD, Francese C, Fontaine F, Ricard M \& Parmentier C. Radioactive iodine treatment and external radiotherapy for lung and bone metastases from thyroid carcinoma. Journal of Nuclear Medicine 199637 598-605.

7 Arturi F, Russo D, Schlumberger M, du VJ, Caillou B, Vigneri P, Wicker R, Chiefari E, Suarez HG \& Filetti S. Iodide symporter gene expression in human thyroid tumors. Journal of Clinical Endocrinology and Metabolism $1998 \mathbf{8 3}$ 2493-2496.

8 Caillou B, Troalen F, Baudin E, Talbot M, Filetti S, Schlumberger M \& Bidart JM. $\mathrm{Na}^{+} / \mathrm{I}^{-}$symporter distribution in human thyroid tissues: an immunohistochemical study. Journal of Clinical Endocrinology and Metabolism $1998 \mathbf{8 3} 4102-4106$.

9 Lazar V, Bidart JM, Caillou B, Mahe C, Lacroix L, Filetti S \& Schlumberger M. Expression of the $\mathrm{Na}^{+} / \mathrm{I}^{-}$symporter gene in human thyroid tumors: a comparison study with other thyroidspecific genes. Journal of Clinical Endocrinology and Metabolism $1999843228-3234$.

10 Marcocci C, Pacini F, Elisei R, Schipani E, Ceccarelli C, Miccoli P, Arganini M \& Pinchera A. Clinical and biologic behavior of bone metastases from differentiated thyroid carcinoma. Surgery 1989 106 960-966.
11 Ruegemer JJ, Hay ID, Bergstralh EJ, Ryan JJ, Offord KP \& Gorman CA. Distant metastases in differentiated thyroid carcinoma: a multivariate analysis of prognostic variables. Journal of Clinical Endocrinology and Metabolism 198867 501-508.

12 Pacini F, Schlumberger M, Dralle H, Elisei R, Smit JW \& Wiersinga W. European consensus for the management of patients with differentiated thyroid carcinoma of the follicular epithelium. European Journal of Endocrinology 2006154 787-803.

13 Cooper DS, Doherty GM, Haugen BR, Kloos RT, Lee SL, Mandel SJ, Mazzaferri EL, McIver B, Sherman SI \& Tuttle RM. Management guidelines for patients with thyroid nodules and differentiated thyroid cancer. Thyroid 200616 109-142.

14 Sobrinho-Simoes M, Preto A, Rocha AS, Castro P, Maximo V, Fonseca E \& Soares P. Molecular pathology of well-differentiated thyroid carcinomas. Virchows Archiv 2005 447 787-793.

15 Fagin JA. How thyroid tumors start and why it matters: kinase mutants as targets for solid cancer pharmacotherapy. Journal of Endocrinology 2004183 249-256.

16 Soares P \& Sobrinho-Simoes M. Recent advances in cytometry, cytogenetics and molecular genetics of thyroid tumours and tumour-like lesions. Pathology, Research and Practice 1995191 304-317.

17 Riesco-Eizaguirre G, Gutierrez-Martinez P, Garcia-Cabezas MA, Nistal M \& Santisteban P. The oncogene BRAF ${ }^{V 600}$ is associated with a high risk of recurrence and less differentiated papillary thyroid carcinoma due to the impairment of $\mathrm{Na}^{+} / \mathrm{I}^{-}$targeting to the membrane. Endocrine-Related Cancer 200613 257-267.

18 Tallini G. Molecular pathobiology of thyroid neoplasms. Endocrine Pathology $200213271-288$.

19 Cinti R, Yin L, Ilc K, Berger N, Basolo F, Cuccato S, Giannini R, Torre G, Miccoli P, Amati P, Romeo G \& Corvi R. RET rearrangements in papillary thyroid carcinomas and adenomas detected by interphase FISH. Cytogenetics and Cell Genetics 2000 88 56-61.

20 Corvi R, Berger N, Balczon R \& Romeo G. RET/PCM-1: a novel fusion gene in papillary thyroid carcinoma. Oncogene 200019 4236-4242.

21 Klugbauer S, Jauch A, Lengfelder E, Demidchik E \& Rabes HM. A novel type of RET rearrangement (PTC8) in childhood papillary thyroid carcinomas and characterization of the involved gene (RFG8). Cancer Research 200060 7028-7032.

22 Nikiforov YE, Rowland JM, Bove KE, Monforte-Munoz H \& Fagin JA. Distinct pattern of ret oncogene rearrangements in morphological variants of radiation-induced and sporadic thyroid papillary carcinomas in children. Cancer Research $1997 \mathbf{5 7}$ 1690-1694.

23 Grieco M, Santoro M, Berlingieri MT, Melillo RM, Donghi R, Bongarzone I, Pierotti MA, Della PG, Fusco A \& Vecchio G. PTC is a novel rearranged form of the ret proto-oncogene and is frequently detected in vivo in human thyroid papillary carcinomas. Cell 1990 $60557-563$.

24 Santoro M, Dathan NA, Berlingieri MT, Bongarzone I, Paulin C, Grieco M, Pierotti MA, Vecchio G \& Fusco A. Molecular characterization of RET/PTC3; a novel rearranged version of the RETproto-oncogene in a human thyroid papillary carcinoma. Oncogene 19949 509-516.

25 Santoro M, Chiappetta G, Cerrato A, Salvatore D, Zhang L, Manzo G, Picone A, Portella G, Santelli G, Vecchio G \& Fusco A. Development of thyroid papillary carcinomas secondary to tissuespecific expression of the RET/PTC1 oncogene in transgenic mice. Oncogene 199612 1821-1826.

26 Santoro M, Carlomagno F, Hay ID, Herrmann MA, Grieco M, Melillo R, Pierotti MA, Bongarzone I, Della PG \& Berger N. Ret oncogene activation in human thyroid neoplasms is restricted to the papillary cancer subtype. Journal of Clinical Investigation 1992 89 1517-1522.

27 Viglietto G, Chiappetta G, Martinez-Tello FJ, Fukunaga FH, Tallini G, Rigopoulou D, Visconti R, Mastro A, Santoro M \& Fusco A. RET/PTC oncogene activation is an early event in thyroid carcinogenesis. Oncogene 199511 1207-1210. 
28 Greco A, Pierotti MA, Bongarzone I, Pagliardini S, Lanzi C \& Della PG. TRK-T1 is a novel oncogene formed by the fusion of TPR and TRK genes in human papillary thyroid carcinomas. Oncogene $19927237-242$.

29 Xing M. BRAF mutation in thyroid cancer. Endocrine-Related Cancer 200512 245-262.

30 Soares P, Trovisco V, Rocha AS, Lima J, Castro P, Preto A, Maximo V, Botelho T, Seruca R \& Sobrinho-Simoes M. BRAF mutations and RET/PTC rearrangements are alternative events in the etiopathogenesis of PTC. Oncogene $2003224578-4580$.

31 Puxeddu E, Moretti S, Elisei R, Romei C, Pascucci R, Martinelli M, Marino C, Avenia N, Rossi ED, Fadda G, Cavaliere A, Ribacchi R, Falorni A, Pontecorvi A, Pacini F, Pinchera A \& Santeusanio F. BRAF(V599E) mutation is the leading genetic event in adult sporadic papillary thyroid carcinomas. Journal of Clinical Endocrinology and Metabolism $2004892414-2420$.

32 Fukushima T, Suzuki S, Mashiko M, Ohtake T, Endo Y, Takebayashi Y, Sekikawa K, Hagiwara K \& Takenoshita S. BRAF mutations in papillary carcinomas of the thyroid. Oncogene 2003 22 6455-6457.

33 Pennell NA, Daniels GH, Haddad RI, Ross DS, Evans T, Wirth LJ, Fidias PH, Temel JS, Gurubhagavatula S, Heist RS, Clark JR \& Lynch TJ. A phase II study of Gefitinib in patients with advanced thyroid cancer. Thyroid 200818 317-323.

34 Cohen EEW, Rosen LS, Vokes EE, Kies MS, Forastiere AA, Worden FP, Kane MA, Sherman E, Kim S, Bycott P, Tortorici M, Shalinsky DR, Liau KF \& Cohen RB. Axitinib is an active treatment for all histologic subtypes of advanced thyroid cancer: results from a phase II study. Journal of Clinical Oncology 200826 4708-4713.

35 Gupta-Abramson V, Troxel AB, Nellore A, Puttaswamy K, Redlinger M, Ransone K, Mandel SJ, Flaherty KT, Loevner LA, O'Dwyer PJ \& Brose MS. Phase II trial of sorafenib in advanced thyroid cancer. Journal of Clinical Oncology 200826 4714-4719.

36 Sherman SI, Wirth LJ, Droz JP, Hofmann M, Bastholt L, Martins RG, Licitra L, Eschenberg MJ, Sun YN, Juan T, Stepan DE, Schlumberger MJ \& The Motesanib Thyroid Cancer Study Group . Motesanib diphosphate in progressive differentiated thyroid cancer. New England Journal of Medicine 2008359 31-42.

37 Kloos RT, Ringel MD, Knopp MV, Hall NC, King M, Stevens R, Liang J, Wakely PEJ, Vasko VV, Saji M, Rittenberry J, Wei L, Arbogast D, Collamore M, Wright JJ, Grever M \& Shah MH. Phase II trial of sorafenib in metastatic thyroid cancer. Journal of Clinical Oncology 200927 1675-1684.
38 De Vita G, Zannini M, Cirafici AM, Melillo RM, Di Lauro R, Fusco A \& Santoro M. Expression of the RET/PTC1 oncogene impairs the activity of TTF-1 and Pax-8 thyroid transcription factors. Cell Growth \& Differentiation 19989 97-103.

39 Fenton MS, Marion K, Salem AK, Hogen R, Naeim F \& Hershman JM. Induction of cell cycle arrest by sunitinib through inhibition of the MEK/ERK pathway in RET/PTC1 papillary thyroid cancer cells. 90th Annual Meeting of the Endocrine Society, San Francisco (abstract), 1990

40 Pluijmen MJ, Eustatia-Rutten C, Goslings BM, Stokkel MP, Arias AM, Diamant M, Romijn JA \& Smit JW. Effects of low-iodide diet on postsurgical radioiodide ablation therapy in patients with differentiated thyroid carcinoma. Clinical Endocrinology $2003 \mathbf{5 8}$ 428-435.

41 Elisei R, Ugolini C, Viola D, Lupi C, Biagini A, Giannini R, Romei C, Miccoli P, Pinchera A \& Basolo F. BRAF ${ }^{\mathrm{V} 600 \mathrm{E}}$ mutation and outcome of patients with papillary thyroid carcinoma: a 15-year median follow-up study. Journal of Clinical Endocrinology and Metabolism 200893 3943-3949.

42 Wapnir IL, van de RM, Nowels K, Amenta PS, Walton K, Montgomery K, Greco RS, Dohan O \& Carrasco N. Immunohistochemical profile of the sodium/iodide symporter in thyroid, breast, and other carcinomas using high density tissue microarrays and conventional sections. Journal of Clinical Endocrinology and Metabolism $2003 \mathbf{8 8} 1880-1888$.

43 Liu YY, Morreau H, Kievit J, Romijn JA, Carrasco N \& Smit JW. Combined immunostaining with galectin-3, fibronectin-1, CITED1, Hector Battifora mesothelial-1, cytokeratin-19, peroxisome proliferator-activated receptor- $\gamma$, and sodium/iodide symporter antibodies for the differential diagnosis of non-medullary thyroid carcinoma. European Journal of Endocrinology 2008158 375-384.

44 Furuya F, Shimura H, Suzuki H, Taki K, Ohta K, Haraguchi K, Onaya T, Endo T \& Kobayashi T. Histone deacetylase inhibitors restore radioiodide uptake and retention in poorly differentiated and anaplastic thyroid cancer cells by expression of the sodium/iodide symporter thyroperoxidase and thyroglobulin. Endocrinology $20041452865-2875$.

45 Salem AK, Fenton MS, Marion KM \& Hershman JM. Effect of sunitinib on growth and function of FRTL- 5 thyroid cells. Thyroid $200818631-635$.

Received 12 September 2009

Accepted 17 September 2009 